\title{
Prevalence, management and burden of episodic and chronic headaches-a cross- sectional multicentre study in eight Austrian headache centres
}

Karin Zebenholzer ${ }^{1 *}$, Colette Andree ${ }^{2,3}$, Anita Lechner $^{4}$, Gregor Broessner $^{5}$, Christian Lampl ${ }^{6}$, Gernot Luthringshausen ${ }^{7}$, Albert Wuschitz ${ }^{8}$, Sonja-Maria Obmann ${ }^{9}$, Klaus Berek ${ }^{10}$ and Christian Wöber ${ }^{1}$

\begin{abstract}
Background: Episodic and chronic headaches $(\mathrm{EH}, \mathrm{CH})$ are highly prevalent disorders. Severely affected patients are usually referred to headache centres. In Austria, at least one headache centre is available in seven of nine states, but detailed multicentre data are missing. Therefore we studied prevalence rates, use of medication and health care services, impact of headaches, and comorbid depression and anxiety.

Methods: We included consecutive patients from eight Austrian outpatient headache centres. The patients filled-in the Eurolight questionnaire. In addition, the treating neurologist completed a questionnaire on clinical diagnoses and ever-before prophylactic medications.

Results: Of 598 patients screened, 441 questionnaires were analysed (79 \% female, mean age 41.1 years). According to the Eurolight algorithm, $56.4 \%$ of the patients had EH, $38.3 \%$ had $\mathrm{CH}$ and $5.2 \%$ did not give their headache frequency. The prevalence rates of migraine, tension-type headache, and probable medication overuse headache $(\mathrm{pMOH})$ were $48.5 \%, 6.3 \%$ and $15.9 \%$, respectively. The concordance between clinical and Eurolight diagnoses was good for $\mathrm{EH}$ and moderate for $\mathrm{CH}$. During the preceding month, acute medication was used by $90.9 \%$ of the patients and prophylactic medication by $34 \%$. Ever-before use of five standard prophylactic drugs was recorded in $52.3 \%$. The proportion of patients with current pharmacoprophylaxis did not differ in $\mathrm{EH}$ and $\mathrm{CH}$, whereas ever-before use was more common in $\mathrm{CH}(62.5 \%$ was $45,3 \%, p=0.02)$. Patients with $\mathrm{CH}$ significantly more often consulted general practitioners and emergency departments, had a lower quality of life and more often signs of depression and anxiety.

Conclusion: This study provides comprehensive data from eight Austrian headache centres for the first time. We found a substantial number of patients with $\mathrm{CH}$ including $\mathrm{pMOH}$ and its association with more common utilization of health care facilities and greater burden. The low use of prophylactic medication requires further examination.
\end{abstract}

Keywords: Episodic headache; Chronic headache; Migraine; Medication overuse headache; Prophylactic treatment; Health care service; Quality of life; Burden; Anxiety; Depression

\footnotetext{
* Correspondence: karin.zebenholzer@meduniwien.ac.at

'Department of Neurology, Medical University of Vienna, Vienna, Austria

Full list of author information is available at the end of the article
} 


\section{Background}

Headache is one of the most frequent neurological disorders interfering with everyday life. The one-year prevalence is $10-18 \%$ in migraine, and $31-90 \%$ in tension-type headache (TTH) [1-3]. For Austria the one-year prevalence of migraine was $10 \%$ [4]. In a European survey migraine was found in $36 \%$, probable medication overuse headache (pMOH) in $3 \%$ and any chronic headache in $7.6 \%$ of the participants during the preceding year. These high prevalence rates were attributed to the study design [5]. Headaches, especially chronic headache and medication overuse headache $(\mathrm{MOH})$, are associated with comorbidities such as depression, anxiety disorders, restless legs syndrome [6-8] and reduced quality of life [9]. The impact on the patients' lives is high with regard to lost workdays, and lost family, social or leisure activities [5]. $\mathrm{MOH}$, with a life-time prevalence of $1-2 \%[1,5]$, often represents a major challenge, exceeding the impact of migraine or TTH on everyday's life [5]. In specialized headache centres, patients with medication overuse can account for $30-45 \%$ of all patients [10-12]. In Austria, at least one headache centre is available in seven of nine states. Data on $\mathrm{MOH}$ are only available from one centre, i.e. the Department of Neurology at the Medical University of Vienna, performing in-patient withdrawal treatment in $40-50 \mathrm{pa}-$ tients every year [13-15]. Detailed multicentre data on $\mathrm{MOH}$ and other frequent headaches, however, are missing. Therefore, we performed a prospective study in eight Austrian headache centres and evaluated (i) the prevalence of episodic (EH) and chronic headaches $(\mathrm{CH})$, (ii) the prevalence of migraine, TTH and $\mathrm{pMOH}$, (iii) the use of acute and prophylactic medication, (iv) the use of health care services, (v) the burden of headache and, (vi) comorbid depression and anxiety.

\section{Methods}

In April 2011 and September 2011 all consecutive patients attending one of eight Austrian headache centres for a first time visit or a follow-up visit were invited to participate in the study. Exclusion criteria were secondary headache except medication overuse headache, fibromyalgia, other chronic pain disorders, and lacking knowledge of German. Four centres were at departments of medical universities (Graz, Innsbruck, Salzburg, Vienna), three centres were at large hospitals (Klagenfurt, Kufstein, Linz) and one centre was a large neurological office in Vienna. The study was approved by the ethics committees of the Medical Universities of Vienna, Graz, Innsbruck and Salzburg, and local ethics committees of the other participating departments.

After giving written informed consent the patients filled in the Eurolight questionnaire covering biographic data, headache symptoms, use of acute and prophylactic medication, former examinations due to headaches, quality of life, symptoms of anxiety and depression, the impact of headache and health related quality of life [16]. The Eurolight questionnaire differentiates EH (headache on $<15$ days/month) from $\mathrm{CH}$ (headache on $\geq$ 15 days/month) and is validated for diagnosing migraine, probable migraine, TTH, probable $\mathrm{TTH}$, and $\mathrm{pMOH}$ according to the International Classification of Headache Disorders, $2^{\text {nd }}$ edition (ICHD-2) [17] and for assessing the impact of headache disorders [16]. Probable $\mathrm{MOH}$ was diagnosed when headaches occurred on $\geq 15$ days per month, lasted $\geq 4 \mathrm{~h}$, and the frequency of acute medication use was $\geq 15$ days/month for simple analgesics and $\geq 10$ days/month for compound analgesics, opioids, triptans, or ergots [5]. The questionnaire does not allow diagnosing chronic migraine or chronic tension-type headache in the strict sense of ICHD-2 or its appendix. Therefore we separated two groups by their headache frequency as given in the questionnaire: patients with $\mathrm{EH}$ and patients with $\mathrm{CH}$. The Eurolight questionnaire also includes the HALT index [18], WHOQoL-8 [19], and the Hospital Anxiety and Depression Scale (HADS) [20]. The HALT index captures in five questions the days lost completely or partially because of headache in the preceding three months and covers professional work, household activities or chores, and family, social or leisure activities [18]. To estimate the burden of headache, and because the data were not normally distributed, we summarized these lost days during the previous three months and categorized the impact of headache into $0-5$ days lost, $6-10$ days lost, 11-20 days lost, and $>20$ days lost. The WHOQoL- 8 produces scores for domains related to quality of life (physical health, psychological, social relationships, environment) and it includes one facet on overall quality of life and general health [19]. The HADS is a screening instrument for depression and anxiety in patients with physical complaints. It is a self-rating questionnaire with two subscales comprising seven items each [20].

The treating neurologist filled in an additional questionnaire covering the clinical headache diagnosis and ever-before intake of five standard prophylactic medications, i.e. betablockers, flunarizine, valproate, topiramate and amitriptyline. For each of these drugs the treating neurologist had to assess, if it was contraindicated and if it ever was taken by the patient. In the latter case, four additional questions had to be answered: Was the treatment stopped because of intolerable adverse effects? Was the taken dose sufficient [21]? Was treatment continued for at least three months? Did the treatment result in a decrease of headache frequency by at least $50 \%$ ? Each of these questions was answered "yes", "no" or "unknown" based on information from the patient and from medical records. 


\section{Statistics}

We applied the standard computerized algorithm to analyse data derived from the Eurolight questionnaire [22]. We used numbers and percentages for descriptive statistics and calculated $\mathrm{Chi}^{2}$ tests for comparing patients with $\mathrm{EH}$ and $\mathrm{CH}$. Two-sided p-values $<0.05$ were considered as statistically significant. For evaluating the concordance between clinical diagnoses and Eurolight diagnoses we defined moderate, good and excellent concordance as agreement of diagnoses in 40-60\%, 61-80\%, and $\geq 81 \%$ respectively. Statistical analyses were performed using SAS version 9.2 and SPSS 20.0.

\section{Results}

We invited 598 consecutive patients, 121 denied participation or had to be excluded. Main reasons for exclusion were lacking fluency in German, particularly at the Medical University of Vienna. Thirty-six questionnaires had to be excluded because of incomplete data. Therefore the final analysis was based on 441 Eurolight questionnaires. The dropout rates per centre ranged from 2 to $14 \%$. We included 111 patients at the department of neurology in Vienna, 76 in Graz, 69 in the neurological practice in Vienna, 51 in Kufstein, 48 in Klagenfurt, 47 in Linz, 24 in Salzburg and 15 in Innsbruck. In addition completed questionnaires on clinical diagnoses and prophylactic medications were available from 392 patients.

\section{Biographic findings}

Ninety-three patients $(21 \%)$ were male and 348 (79 \%) were female. The proportion of female patients ranged from 64.6 to $87.5 \%$ in the eight study centres. The patients' mean age was $41.1 \pm 14.0$ years (16-79) with a range of 32.4-45.6 years (mean) in the eight centres. The patients' occupational status is shown in Table 1.

Table 1 Occupation and income, comparison between patients with $\mathrm{EH}$ and $\mathrm{CH}$

\begin{tabular}{lllllll}
\hline & $\mathrm{EH} n=249$ & $\mathrm{CH} n=169$ & $\mathrm{Chi}^{2}$ & $p$ \\
\hline & $\mathrm{n}$ & $\%$ & $\mathrm{n}$ & $\%$ & & \\
Occupation, missing data: 23 & & & & & & \\
Employee & 168 & 70.6 & 79 & 49.4 & & \\
Housewife/househusband & 5 & 2.1 & 13 & 8.1 & & \\
Student & 28 & 11.8 & 17 & 10.6 & & \\
Unemployed & 11 & 4.6 & 24 & 15.0 & & \\
Retired & 26 & 10.9 & 27 & 16.9 & 29.0 & $<0.0001$ \\
Income, missing data: 49 & & & & & & \\
$<1500$ Euro/month & 105 & 44.9 & 103 & 65.2 & & \\
1500-3500 Euro/month & 115 & 49.1 & 48 & 30.4 & & \\
$>$ 3500 Euro/month & 14 & 6.0 & 7 & 4.4 & 17.2 & 0.018 \\
\hline
\end{tabular}

$\mathrm{EH}$, Episodic headache, $\mathrm{CH}$, Chronic headache

\section{Headache chronicity}

Two-hundred-forty-nine patients $(56.5 \%)$ had EH and 169 (38.3\%) patients had $\mathrm{CH}$, in 23 the patients' frequency data were missing. The prevalence of $\mathrm{CH}$ showed a wide range of $17.2-56.8 \%$ in the eight headache centres, with the lowest rate in the neurological office and the highest in Klagenfurt. Age did not differ in patients with $\mathrm{EH}$ and $\mathrm{CH}$, whereas the percentage of males was higher in $\mathrm{CH}$ than in $\mathrm{EH}(30 \%$ vs. $14.7 \%$; Chi2 $=13.5, p<0.001$ ).

\section{Headache diagnoses}

Among all patients, 214 (48.5 \%) had migraine (thereof 85 probable migraine), 28 (6.3\%) had TTH (thereof 10 probable TTH), 70 (15.9\%) had pMOH, 99 (22.4\%) had $\mathrm{CH}$ not further specified by the Eurolight algorithm, and $7(1.6 \%)$ had other headaches. When the diagnosis $\mathrm{CH}$ or $\mathrm{pMOH}$ was made, or the patients did not give their headache frequency, the Eurolight algorithm did not allow differentiating between migraine, TTH and other headaches. However, all patients had to give the characteristics of their most bothersome headache type. Accordingly some differentiation is possible and summarized in Table 2.

The clinical diagnosis was concordant with the Eurolight diagnosis in 181 patients (78 \%) with EH and in 102 patients $(63.7 \%)$ with $\mathrm{CH}$. In the majority of patients with conflicting diagnoses the Eurolight diagnoses were probable migraine, probable TTH or other headaches.

\section{Medication}

According to the Eurolight questionnaire most patients $(90.9 \%)$ used acute medication to treat their headache attacks during the past month. The proportion was significantly lower in $\mathrm{CH}$ than in $\mathrm{EH}(86.9 \%$ vs. $94.4 \%$; Chi2 $7.1 ; p=0.008$ ). Only $34 \%$ of the patients reported any prophylactic medication at the time of the survey and there was no statistically significant difference between $\mathrm{EH}$ and $\mathrm{CH}$.

According to the additional questionnaire completed by the treating neurologists and covering betablockers, flunarizine, topiramate, valproic acid and amitriptyline, amitriptyline was previously or currently used most frequently (30.4\% of the patients) and valproic acid was used least frequently (7.4 \% of the patients). In total, $52.3 \%$ of the patients had ever used any prophylactic drug: $31.6 \%$ had used one drug, $10.5 \%$ two drugs and $10.2 \%$ three or more. Significantly fewer patients with $\mathrm{EH}$ had ever-before used prophylactic drugs than patients with $\mathrm{CH}\left(45.3 \%\right.$ vs. $62.5 \%$; $\left.\mathrm{Chi}^{2}=12.3, p=0.02\right)$. Fig. 1 shows details of prophylactic drug use: Significantly more patients with $\mathrm{CH}$ had ever used amitriptyline and valproic acid than patients with EH. Except for flunarizine $(19.4 \%)$ the rate of contraindications was 
Table 2 Comparison of headache diagnoses in patients with chronic headache and patients with missing headache frequency based on the "worst headache" in the Eurolight questionnaire

\begin{tabular}{|c|c|c|c|c|c|c|c|c|}
\hline \multirow[t]{3}{*}{ HA diagnosis (worst HA) } & \multicolumn{2}{|l|}{$\mathrm{CH}$} & \multicolumn{2}{|c|}{$\mathrm{CH}$ with $\mathrm{pMOH}$} & \multicolumn{2}{|c|}{$\mathrm{CH}$ without $\mathrm{pMOH}$} & \multicolumn{2}{|c|}{ HA frequency missing } \\
\hline & $n=1$ & & $n=$ & & $n=$ & & $n=$ & \\
\hline & $n$ & $\%$ & $\mathrm{n}$ & $\%$ & $n$ & $\%$ & $\mathrm{~N}$ & $\%$ \\
\hline Migrainous HA & 137 & 81.1 & 66 & 94.3 & 71 & 71.7 & 16 & 69.6 \\
\hline Tension-type like HA & 27 & 16 & 3 & 4.3 & 24 & 24.2 & 5 & 21.7 \\
\hline Other HA & 5 & 3 & 1 & 1.4 & 4 & 4 & 2 & 8.7 \\
\hline
\end{tabular}

$\mathrm{HA}$, Headache, $\mathrm{CH}$, Chronic headache, $\mathrm{pMOH}$, Probable medication overuse headache

below $10 \%$. Significantly more patients with $\mathrm{EH}$ using betablockers or topiramate had a frequency reduction of at least $50 \%($ Chi2 $=9.9, p=0.0019$; Chi $2=7.0, p=0.046)$. Using a sufficient dose [21] was most common for flunarizine $(89.8 \%)$ and least common for betablockers (72.5 \%). More than $60 \%$ of patients that were prescribed any of these prophylactic medications kept on taking them for more than three months.

\section{Use of health care services}

Table 3 shows the use of health care services due to headache. Remarkably, the proportion of patients who had sought help in an emergency department was only $4.4 \%$ in patients from the neurological office, but 13.3$19.2 \%$ in patients from hospital based headache centres. Although patient numbers were relatively small for comparisons, patients with $\mathrm{CH}$ consulted a general practitioner or emergency department significantly more often than patients with EH. Magnetic resonance imaging (MRI) or computed tomography (CT) of the brain was done in $29.5 \%$ of the patients with $\mathrm{CH}$ and in $32.7 \%$ of the patients with $\mathrm{EH}$ during the previous year.

\section{Burden of headache, comorbidity}

About one third of the patients (34.3\%) reported a negative impact of their headache on their career and $21.5 \%$ indicated that their headaches had negative impact on their earnings. Only $49.9 \%$ of the patients had the impression that their colleagues at work accepted their headaches. Significantly more patients with $\mathrm{CH}$ than with $\mathrm{EH}$ were unemployed or retired, and patients with $\mathrm{CH}$ had significantly lower incomes (Table 1 ).

Table 4 shows the cumulative number of lost days according to the HALT index. Patients with $\mathrm{CH}$ had a significantly higher burden. This categorization does not yield intuitive information about the amount of

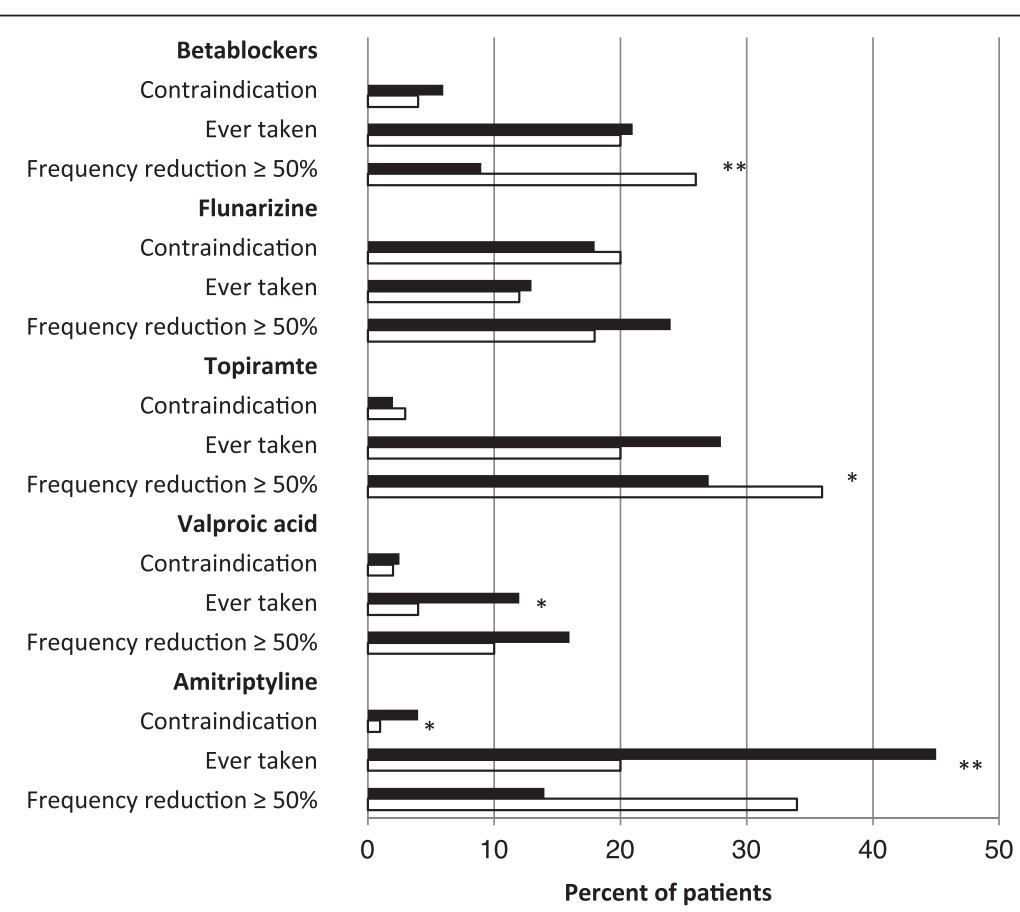

Fig. 1 Percentages of patients with contraindications against, ever-before use of, and frequency reduction by $\geq 50 \%$ by five standard prophylactic drugs for migraine and/or TTH in EH compared to $\mathrm{CH}$, White bars = episodic headache, black bars = chronic headache, ${ }^{*} p<0.05$; ${ }^{* *} p<0.001$ 
Table 3 Differences in the utilization of health care services between patients with episodic headache and chronic headache

\begin{tabular}{|c|c|c|c|c|c|c|c|c|}
\hline \multirow{2}{*}{$\begin{array}{l}\text { Health care services } \\
\text { Frequency data missing } 23\end{array}$} & \multicolumn{2}{|c|}{ All patients } & \multicolumn{2}{|l|}{$\mathrm{EH}$} & \multicolumn{2}{|l|}{$\mathrm{CH}$} & \multirow[t]{2}{*}{$\mathrm{Chi}^{2}$} & \multirow[t]{2}{*}{$P$} \\
\hline & $\mathrm{n}$ & $\%$ & $n$ & $\%$ & $\mathrm{n}$ & $\%$ & & \\
\hline General practitioner & 146 & 33.1 & 72 & 30.0 & 66 & 40.5 & 4.7 & 0.029 \\
\hline Neurologist & 286 & 64.9 & 165 & 69.3 & 109 & 66.5 & 0.37 & n.s. \\
\hline Physical therapist & 99 & 22.5 & 40 & 17.1 & 54 & 32.7 & 0.27 & n.s. \\
\hline Emergency department & 63 & 14.3 & 34 & 14.7 & 27 & 16.6 & 13.1 & 0.0003 \\
\hline
\end{tabular}

time actually lost. But the range of lost days was very wide (0-90), and therefore mean values or medians do not reflect the true loss satisfactorily, either. Only few patients accounted for a disproportional part of the reported burden; 26 (5.9\%) patients reported $\geq 45$ lost days in at least one of lost work, housework or social days. The patients' health-related quality of life, anxious and depressive state are shown in Table 4. Patients with $\mathrm{CH}$ had significantly more symptoms of anxiety and depression than patients with EH. Quality of life was significantly worse in patients with $\mathrm{CH}$ than in patients with EH. Table 5 gives quality of life, depression and anxiety in patients with $\mathrm{CH}$ with and without $\mathrm{pMOH}$ and shows no statistically significant differences.

\section{Discussion}

For the first time this cross-sectional, prospective, multicentre study provides comprehensive data from eight Austrian headache centres. Of 441 patients included $57 \%$ had EH, $38 \%$ had $\mathrm{CH}$ and $5 \%$ did not give their headache frequency. The prevalence of migraine, TTH and $\mathrm{pMOH}$ was $49 \%, 6 \%$ and $16 \%$, respectively. In the previous month, the vast majority-more than $90 \%$ - of the patients had used acute medication. The percentage was higher in $\mathrm{EH}$ than in $\mathrm{CH}$. The proportion of

Table 4 Quality of life, anxiety, depression and burden of headache in all patients and in patients with episodic and chronic headache

\begin{tabular}{|c|c|c|c|c|c|c|c|c|}
\hline & \multicolumn{2}{|c|}{ All patients } & \multicolumn{2}{|l|}{$\mathrm{EH}$} & \multicolumn{2}{|l|}{$\mathrm{CH}$} & \multirow[b]{2}{*}{$\mathrm{Chi}^{2}$} & \multirow[b]{2}{*}{$p$} \\
\hline & $\mathrm{n}$ & $\%$ & $n$ & $\%$ & $\mathrm{n}$ & $\%$ & & \\
\hline Quality of life & & & & & & & 38.2 & $<0.0001$ \\
\hline \multicolumn{9}{|l|}{ Missing data 28} \\
\hline Very poor & 18 & 4.2 & 3 & 1.2 & 13 & 7.9 & & \\
\hline Poor & 34 & 7.8 & 11 & 4.4 & 20 & 12.2 & & \\
\hline Neither good nor poor & 100 & 23.0 & 44 & 17.7 & 50 & 30.5 & & \\
\hline Good & 199 & 45.9 & 137 & 55.0 & 55 & 33.6 & & \\
\hline Very good & 83 & 19.1 & 54 & 21.7 & 26 & 15.9 & & \\
\hline HADS Anxiety & & & & & & & 19.6 & $<0.0001$ \\
\hline \multicolumn{9}{|l|}{ Missing data 37} \\
\hline No anxiety & 241 & 54.6 & 160 & 65.6 & 74 & 46.3 & & \\
\hline Possible anxiety & 79 & 17.9 & 45 & 18.4 & 32 & 20.0 & & \\
\hline Probable anxiety & 102 & 23.1 & 39 & 16.0 & 54 & 33.8 & & \\
\hline HADS Depression & & & & & & & 39.0 & $<0.0001$ \\
\hline \multicolumn{9}{|l|}{ Missing data 45} \\
\hline No depression & 281 & 63.7 & 186 & 77.8 & 86 & 54.8 & & \\
\hline Possible depression & 76 & 17.2 & 41 & 17.2 & 30 & 19.1 & & \\
\hline Probable depression & 58 & 13.3 & 12 & 5.0 & 41 & 26.1 & & \\
\hline \multicolumn{9}{|l|}{ HALT Index } \\
\hline \multicolumn{9}{|l|}{ Missing data 54} \\
\hline 0-5 days lost & 96 & 24.8 & 67 & 29.4 & 25 & 17.6 & 32 & $<0.001$ \\
\hline 6-10 days lost & 50 & 12.9 & 38 & 17.7 & 9 & 6.3 & & \\
\hline 11-20 days lost & 66 & 17.1 & 46 & 20.2 & 18 & 12.7 & & \\
\hline$>20$ days lost & 175 & 45.2 & 77 & 33.8 & 90 & 63.4 & & \\
\hline
\end{tabular}


Table 5 Quality of life, anxiety and depression in patients with chronic headache with and without probable medication overuse headache

\begin{tabular}{|c|c|c|c|c|c|c|}
\hline & \multicolumn{2}{|c|}{$\mathrm{CH}$ with $\mathrm{pMOH}$} & \multicolumn{2}{|c|}{$\mathrm{CH}$ without $\mathrm{pMOH}$} & \multirow[b]{2}{*}{$\mathrm{Chi}^{2}$} & \multirow[b]{2}{*}{$p$} \\
\hline & $\mathrm{n}$ & $\%$ & $n$ & $\%$ & & \\
\hline Quality of life & & & & & 3.0 & n.s. \\
\hline Missing data & 3 & & 2 & & & \\
\hline Very poor & 7 & 10,4 & 6 & 6,2 & & \\
\hline Poor & 9 & 13,4 & 11 & 11,3 & & \\
\hline Neither good nor poor & 21 & 31,3 & 29 & 29,9 & & \\
\hline Good & 22 & 32,8 & 33 & 34,0 & & \\
\hline Very good & 8 & 11,9 & 18 & 18,6 & & \\
\hline HADS Anxiety & & & & & 2.9 & n.s. \\
\hline Missing data & 6 & & 3 & & & \\
\hline No anxiety & 28 & 40.0 & 46 & 46.5 & & \\
\hline Possible anxiety & 11 & 15.7 & 21 & 21.2 & & \\
\hline Probable anxiety & 25 & 35.7 & 29 & 29.3 & & \\
\hline HADS Depression & & & & & 3.9 & n.s. \\
\hline Missing data & 6 & & 6 & & & \\
\hline No depression & 32 & 45.7 & 55 & 55.6 & & \\
\hline Possible depression & 12 & 17.1 & 18 & 18.2 & & \\
\hline Probable depression & 20 & 28.6 & 20 & 20.2 & & \\
\hline
\end{tabular}

$\mathrm{CH}$, Chronic headache, $\mathrm{pMOH}$, Probable medication overuse headache

patients who had used prophylactic drugs in the previous month was only $34 \%$ and there was no difference between $\mathrm{EH}$ and $\mathrm{CH}$. Even the proportion of patients who ever-before had used at least one of five standard prophylactic drugs, i.e. betablockers, flunarizine, topiramate, valproic acid and amitriptyline was not higher than $52 \%$. During the previous year two thirds of the patients had undergone MRI or CT and one out of seven attended an emergency department because of headache. Health related quality of life was poor or very poor in $12 \%$ of the patients, more than $20 \%$ indicated that their headaches had a negative impact on their earnings, one third experienced a negative impact on their career. The burden of headache in terms of lost days because of headache was severe in $45 \%$ with more than 20 lost days in the preceding three months, and only half of the patients had noticed that their colleagues at work accepted their headaches. Symptoms of anxiety and depression, present in $45 \%$ and $30 \%$, respectively, were significantly more present in $\mathrm{CH}$ than in $\mathrm{EH}$.

\section{Headache chronicity and diagnoses}

The greater proportion of males among patients with $\mathrm{CH}$ compared to EH should not only be seen as a selection bias, but might suggest that males are less likely to seeking help or being referred to a headache centre, if they have less frequent headaches. An epidemiological survey showed that more females than males with headache consulted their general practitioner [23]. With respect to the diagnostic spectrum, the majority of the patients with $\mathrm{EH}$ had migraine or probable migraine, and the vast majority of the patients with $\mathrm{CH}$ with or without $\mathrm{pMOH}$ was suffering from migrainous headache, comparable to previously published studies [12]. The percentage of patients with $\mathrm{pMOH}$ was 38-65\% smaller than in other studies $[10,11]$. This may be due to different health systems in general, to different referral systems and to different study designs. In contrast to Austria, the Danish headache centre is the only tertiary headache centre in Denmark for 5 million inhabitants [10]. Referral regulations are less restrictive in Austria. Although patients should be referred to headache centres by neurologists, a substantial number of patients attends specialized headache centres on self-referral or on referral by their general practitioner. Bigal et al. [11] included patients with transformed migraine only in their study. Unexpectedly, the number of patients classified as $\mathrm{CH}$ without $\mathrm{pMOH}$ was high (99 of 169 patients). This may be caused by the cross-sectional study design.

The concordance between clinical diagnoses and Eurolight diagnoses was good for $\mathrm{EH}$ and moderate for $\mathrm{CH}$. Conflicting diagnoses were associated with Eurolight diagnoses of probable migraine, probable TTH and other headaches. In clinical practice, neurologists tended to diagnose definite migraine or TTH more often. The Eurolight diagnosis of $\mathrm{pMOH}$ corresponded with the clinical diagnosis of $\mathrm{MOH}$ in only $52 \%$. The main reason for this discrepancy may be, that the Eurolight questionnaire covers the preceding four weeks, whereas clinically $\mathrm{MOH}$ was diagnosed, if the patients had overused acute medications for at least three months (according to ICHD-2). Moreover, some patients' history did not indicate a clearcut overuse. Two patients had cluster headache and were not considered as having $\mathrm{MOH}$ during their cluster episode despite their frequent use of triptans.

\section{Medication}

The smaller percentage of patients with $\mathrm{CH}$ compared to those with $\mathrm{EH}$ who had used acute medication during the previous month may be explained by differences in the proportion of TTH or TTH-like headache, which was $11 \%$ in $\mathrm{EH}, 16 \%$ in $\mathrm{CH}$ and $24 \%$ in $\mathrm{CH}$ without $\mathrm{pMOH}$.

Patients with $\mathrm{CH}$ had ever used prophylactic drugs significantly more often than patients with $\mathrm{EH}$. This was driven by two drugs: ever-before use of amitriptyline and valproic acid was more common in $\mathrm{CH}$. In general, the proportion of patients using any prophylactic medication was comparable to other patient populations [11, 12]. Seen from the aspect that $38 \%$ of the patients had $\mathrm{CH}$, and only $39 \%$ of them had used prophylactic medication 
during the previous month and $52 \%$ had ever used one of five standard prophylactic drugs, patients with $\mathrm{CH}$ are undertreated. Since many patients taking part in the study were seen at the tertiary care centres for the first time, this reflects insufficient treatment in primary care and in neurological offices.

\section{Use of health care services}

During the previous year patients with $\mathrm{CH}$ consulted general practitioners and emergency departments significantly more often than those with EH. Similarly, a populationbased study from the USA [24] showed that the consultation of most health care professionals is numerically more common in chronic than in episodic migraine. Formal tests for statistically significant differences were not performed in this study [24].

The frequent use of neuroimaging as demonstrated in our sample is also reflected in a recent study from the USA [25]. This study covered more than 50 million patient visits with an ICD-9 diagnosis of headache and showed utilization of MRI or CT in $12.8 \%$ of all visits for any headaches, in $10.2 \%$ of the visits for headaches without red flags and in $9.8 \%$ of all visits for any migraine. Even though our findings and the results of the US study cannot be compared because of different methods, both studies indicate overuse of MRI and CT in primary headaches. The emphasis on neuroimaging is also reflected by comparing the percentage of patients who had an MRI and/or CT during the previous year, i.e. $65.7 \%$, to that who had currently taken prophylactic medication, i.e. $34 \%$. The overuse of imaging and the underuse of prophylactic medication require further investigations to elucidate the role of the physicians and of the patients in this issue. On the one hand physicians may overuse imaging to defend themselves from the risk of misdiagnosis. On the other hand, daily clinical experience is such, that many patients with a long-lasting headache history want another MRI after some years. Sometimes these patients seem to be dissatisfied with their treatment or they fear a malignant disease, and it may be that in busy offices the easiest way to deal with this is to write a referral. It also points to the necessity of more continuing education for general practitioners and neurologists in the field of headache.

\section{Burden of headache}

The burden of headache differs not only between patients with $\mathrm{EH}$ and $\mathrm{CH}$, with the latter being affected more severely, but there seems to be also a relation to the type of the questions or questionnaires. Sixty-two percent of the patients reported at least 11 lost days during the preceding three months because of headache. In contrast, quality of life assessed by means of WHOQoL-8 was good or very good in $66 \%$ and poor or very poor in $12 \%$ only.
It was demonstrated that chronic migraine imposes a greater burden on the individual patient than episodic migraine in terms of lower quality of life and headache impact [12, 26, 27], and that patients with chronic migraine or $\mathrm{pMOH}$ had more workdays lost, more days with reduced productivity and more days lost for family or leisure activities than patients with episodic migraine $[5,12]$. A recent study on headache yesterday in Russia showed that headache yesterday reduced productivity in $70 \%$ of the patients [28]; likewise in an African cohort $68 \%$ of patients with headache lost workdays [29]. Data on TTH are sparse, but a recent study found similar results for patients with chronic TTH [30]. In a longitudinal study patients with chronic migraine had lower household incomes and worked part-time more often than patients with episodic migraine [7]. Also, in our study a substantial number of patients experienced a negative impact on earnings and careers and they missed acceptance of their headaches at work.

\section{Psychiatric comorbidity}

Psychiatric comorbidity, in particular depression and anxiety, has been studied extensively in patients with recurrent or chronic headaches [31]. The proportion of patients with evidence of anxiety and depression in our study was comparable to previous studies [31]. Similarly, our findings agree with the literature regarding a higher prevalence of depression and anxiety in patients with $\mathrm{CH}$ compared to those with EH [7, 32]. Patients with psychiatric comorbidity are at higher risk for chronic migraine and $\mathrm{MOH}$ [31]. Future studies should (further) clarify the impact of anxiety and depression on the use of healthcare services, treatment and burden of headache.

\section{Strengths and limitations}

This was the first study in Austria investigating the prevalence, management and burden of $\mathrm{EH}$ and $\mathrm{CH}$ in specialized headache outpatient centres. Strengths are that all important headache centres participated in the study, the high participation rate among patients, and that we assessed clinical diagnoses in addition to Eurolight diagnoses. Possible limitations are that the Eurolight questionnaire does not allow to differentiate $\mathrm{CH}$, and that the additional questionnaire on prophylactic medications was based on retrospective assessments and therefore may suffer from recall bias.

\section{Conclusion}

In conclusion we provided detailed data on the prevalence, management and impact of headache in eight Austrian headache centres. A substantial number of patients has $\mathrm{CH}$, including $\mathrm{pMOH}$, and these patients utilize health care facilities more often and suffer from a greater impact 
of headache on their daily lives. Future studies should elucidate the reasons for the overuse of neuroimaging and the underuse of pharmacoprophylaxis as well as the impact of anxiety and depression on the management of recurrent or chronic headaches. Finally, our future efforts must aim at reducing the burden of headache by reducing imaging and improving pharmacological treatment.

\section{Competing interests}

KZ received honoraria for advisory boards and travel funding from Allergan and travel funding from Menarini, CA declares she has no competing interests, AL received honoraria from Allergan, GB received honoraria from Allergan, CL serves on scientific advisory boards for Allergan and received funding for travel from Bayer Schering Pharma, Merck Serono, and Teva Pharmaceutical Industries Ltd.; serves as a consultant to Allergan and Bayer Schering Pharma; receives research support from Allergan and Bayer Schering Pharma; received personal compensation for consultations or lectures from Bayer HealthCare, Sanofi Aventis, Biogen Idec, Teva Pharmaceuticals. GL received honoraria from Allergan, AW declares he has no competing interests, SMO declares she has no competing interests, KB declares he has no competing interests, CW received honoraria from Allergan and Pfizer, is consultant to Curelator.

\section{Authors' contributions}

KZ conceived the study, contributed to data acquisition and statistical analysis and drafted the manuscript. CA contributed to the statistical analysis. AL contributed to the design of the study and contributed to data acquisition. GB conceived the study and contributed to data acquisition. $\mathrm{CL}$ participated in the study design and contributed to data acquisition. GL, AW, $\mathrm{SO}$ and $\mathrm{KB}$ contributed to the design of the study and data acquisition. CW conceived the study, contributed to data acquisition and drafting of the manuscript and revised the manuscript critically. All authors read and approved the final manuscript.

\section{Acknowledgment}

We thank the Steering Committee of the Eurolight Project for allowing us to use the Eurolight questionnaire.

We thank Marlene Fischer, Walter Wurm, Stefan Leis, Florian Ernst, Bernadette Ramprecht, Almut Veith, Sabine Misslinger and Martin Sawires for their help in patient recruitment.

This study was partly funded by an unrestricted scientific grant from Allergan. However, Allergan was not involved in study design, collection, analysis and interpretation of data, writing of the manuscript and in the decision to submit the manuscript for publication.

\section{Author details}

'Department of Neurology, Medical University of Vienna, Vienna, Austria. ${ }^{2}$ CRP Santé, Strassen, Luxemburg. ${ }^{3}$ University Basle Department of Pharmaceutical Sciences, Basel, Switzerland. ${ }^{4}$ Department of Neurology, Medical University of Graz, Graz, Austria. ${ }^{5}$ Department of Neurology, Medical University of Innsbruck, Innsbruck, Austria. ${ }^{6}$ Headache Centre Seilerstätte, Hospital Sisters of Charity Linz, Linz, Austria. ${ }^{7}$ University Clinic of Neurology, Christian-Doppler-Klinik Salzburg, Salzburg, Austria. ${ }^{8}$ Neurological Office Vienna, Vienna, Austria. ${ }^{9}$ Department of Neurology, Klinikum Klagenfurt, Klagenfurt, Austria. ${ }^{10}$ Department of Neurology, a.ö. KH Kufstein, Kufstein, Austria.

Received: 23 March 2015 Accepted: 10 May 2015

Published online: 19 May 2015

\section{References}

1. Stovner LJ, Andree C (2010) Prevalence of headache in Europe: a review for the Eurolight project. J Headache Pain 11:289-99

2. Vos T, Flaxman AD, Naghavi M, Lozano R, Michaud C, Ezzati M, Shibuya K, Salomon JA, Abdalla S, Aboyans V, Abraham J, Ackerman I, Aggarwal R, Ahn SY, Ali MK, Alvarado M, Anderson HR, Anderson LM, Andrews KG, Atkinson C, Baddour LM, Bahalim AN, Barker-Collo S, Barrero LH, Bartels DH, Basáñez MG, Baxter A, Bell ML, Benjamin EJ, Bennett D et al (2012) Years lived with disability (YLDs) for 1160 sequelae of 289 diseases and injuries 1990-2010: a systematic analysis for the Global Burden of Disease Study. Lancet 380:2163-96

3. Stovner LJ, Zwart JA, Hagen K, Terwindt G, Pascual J (2006) Epidemiology of headache in Europe. Eur J Neurol 13:333-45

4. Lampl C, Buzath A, Baumhackl U, Klingler D (2003) One-year prevalence of migraine in Austria: a nation-wide survey. Cephalalgia 23(4):280-6

5. Steiner TJ, Stovner LJ, Katsarava Z, Lainez JM, Lampl C, Lanteri-Minet M, Rastenyte D, Ruiz de la Torre E, Tassorelli C, Barre J, Andree C (2014) The impact of headache in Europe: principal results of the Eurolight project. J Headache Pain 15:31-41

6. Katsarava Z, Obermann M (2013) Medication-overuse headache. Curr Opin Neurol 26:276-81

7. Buse DC, Manack A, Serrano D, Turkel C, Lipton RB (2010) Sociodemographic and comorbidity profiles of chronic migraine and episodic migraine sufferers. J Neurol Psychiatr 81:428-32

8. Zanigni S, Giannini G, Melotti R, Pattaro C, Provini F, Cevoli S, Facheris MF, Cortelli P, Pramstaller PP (2014) Association between restless legs syndrome and migraine: a population-based study. Eur J Neurol 21(9):1205-10

9. Stovner LJ, Andree C (2008) Impact of headache in Europe: a review for the Eurolight project. J Headache Pain 9:139-46

10. Zeeberg P, Olesen J, Jensen R (2006) Probable medication-overuse headache. The effect of a 2-month drug-free period. Neurology 27;66(12):1894-8

11. Bigal ME, Rapoport AM, Sheftell FD, Tepper SJ, Lipton RB (2004) Transformed migraine and medication overuse headache in a tertiary headache centre - clinical characteristics and treatment outcomes. Cephalalgia 24:482-90

12. Bigal ME, Lipton RB (2008) Excessive acute migraine medication use and migraine progression. Neurology 25(71):1821-8

13. Schnider P, Aull S, Baumgartner C, Marterer A, Wöber C, Zeiler K, Wessely P (1996) Long-term outcome of patients with headache and drug abuse after inpatient withdrawal: five-year follow-up. Cephalalgia 16(7):481-5

14. Tribl GG, Schnider P, Wöber C, Aull S, Auterith A, Zeiler K, Wessely P (2001) Are there predictive factors for long-term outcome after withdrawal in drug-induced chronic daily headache? Cephalalgia 21(6):691-6

15. Zebenholzer K, Thamer M, Wöber C (2012) Quality of life, depression, and anxiety 6 months after inpatient withdrawal in patients with medication overuse headache: an observational study. Clin J Pain 28(4):284-90

16. Andree C, Vaillant M, Barre J, Katsarava Z, Lainez JM, Lair ML, Lanteri-Minet M, Lampl C, Steiner TJ, Stovner ப, Tassorelli C, Sandor PS (2010) Development and validation of the Eurolight questionnaire to evaluate the burden of primary headache disorders in Europe. Cephalalgia 30:1082-100

17. Headache Classification Subcommittee of the International Headache Society (2004) The International Classification of Headache Disorders: 2nd edition. Cephalalgia 24(Suppl):1-160

18. Steiner TJ (2007) The HALT and HART indices. J Headache Pain 8:S22-5

19. The WHOQOL Group (1998) Development of the World Health Organization WHOQOL-BREF quality of life assessment. Psychol Med 28:551-8

20. Herrmann-Lingen C, Buss U, Snaith RP (2011) Hospital Anxiety and Depression Scale - Deutsche Version (HADS-D). Verlag Hans Huber, Bern

21. Evers S, Áfra J, Frese A, Goadsby PJ, Linde M, May A, Sándor P (2009) EFNS guidelines on the drug treatment of migraine - revised report of an EFNS task force. Eur J Neurol 16:968-91

22. Steiner TJ, Gururaj G, Andree C, Katsarava Z, Ayzenberg I, Yu SY, Al Jumah M, Tekle-Haimanot R, Birbeck GL, Herekar A, Linde M, Mbewe E, Manandhar K, Risal A, Jensen R, Queiroz LP, Scher Al, Wang SJ, Stovner $\sqcup$ (2014) Diagnosis, prevalence estimation and burden measurement in population surveys of headache: presenting the HARDSHIP questionnaire. J Headache Pain 15:3

23. Kristofferson ES, Grande RB, Aaseth K, Lundquist C, Russel MB (2012) Management of primary chronic headache in the general population: the Akershus study of chronic headache. J Headache Pain 13:113-20

24. Bigal ME, Serrano D, Reed M, Lipton RB (2008) Chronic migraine in the population: burden, diagnosis, and satisfaction with treatment. Neurology 71:559-66

25. Callaghan BC, Kerber KA, Pace RJ, Skolarus L, Cooper W, Burke JF (2015) Headache neuroimaging: Routine testing when guidelines recommend against them. Cephalalgia doi:10.1177/0333102415572918

26. Blumenfeld A, Varon S, Wilcox TK, Buse D, Kawata AK, Manack A, Goadsby PJ, Lipton RB (2011) Disability, HRQoL and resource use among chronic and episodic migraineurs: results from the International Burden of Migraine Study (IMBS). Cephalalgia 31:301-15 
27. Buse DC, Manack AN, Serrano D, Varon SF, Turkel LRB (2012) Headache impact of chronic and episodic migraine: predictors of impact from the American Migraine Prevalence and Prevention (AMPP) study. Headache 52(1):3-17

28. Ayzenberg I, Katsarava Z, Sborowski A, Obermann M, Chernysh M, Osipova V, Tabeeva G, Steiner TJ (2015) Headache yesterday in Russia: its prevalence and impact, and their application in estimating the national burden attributable to headache disorders. J Headache Pain 15:7

29. Mengistu G, Alemayehu S (2013) Prevalence and burden of primary headache disorders among a local community in Addis Abeba, Ethiopia. $J$ Headache Pain 14(1):30

30. Rausa M, Cevoli S, Sancisi E, Grimaldi D, Pollutri G, Casoria M, Grieco D, Bisi A, Cortelli P, Pozzi E, Perangeli G (2013) Personality traits in chronic daily headache patients with and without psychiatric comorbidity: an observational study in a tertiary care headache centre. J Headache Pain 14(1):22-8

31. Radat F, Swendsen J (2005) Psychiatric comorbidity in migraine: a review. Cephalalgia 25:165-78

32. Buse DC, Silberstein SD, Manack AN, Papapetropoulos S, Lipton RB (2013) Psychiatric comorbidities of episodic and chronic migraine. J Neurol 260:1960-9

\section{Submit your manuscript to a SpringerOpen ${ }^{\circ}$ journal and benefit from:}

- Convenient online submission

- Rigorous peer review

- Immediate publication on acceptance

- Open access: articles freely available online

- High visibility within the field

- Retaining the copyright to your article 